\title{
ACCELERATION TECHNIQUES FOR RECOMBINATION OF GASES IN ELECTROLYSIS MICROACTUATORS WITH NAFION®-COATED ELECTROCATALYST
}

\author{
Roya Sheybani ${ }^{1}$ and Ellis Meng ${ }^{1,2,3}$
}

\begin{abstract}
${ }^{1}$ Department of Biomedical Engineering, Viterbi School of Engineering, University of Southern California, 1042 Downey Way, DRB-140, Los Angeles, CA 90089-1111, USA

${ }^{2}$ Department of Electrical Engineering, Viterbi School of Engineering, University of Southern California, 3651 Watt Way, VHE-602, Los Angeles, CA 90089-0241, USA

${ }^{3}$ Corresponding Author: Ellis Meng
\end{abstract}

Phone: (213) 740-6952

Fax: (213) 821-3897

E-mail: ellis.meng@usc.edu

\begin{abstract}
Recombination of electrolysis gases (oxidation of hydrogen and reduction of oxygen) is an important factor in operation efficiency of devices employing electrolysis such as actuators and also unitized regenerative fuel cells. Several methods of improving recombination speed and repeatability were developed for application to electrolysis microactuators with Nafion ${ }^{\circledR}$-coated catalytic electrodes. Decreasing the electrolysis chamber volume increased the speed, consistency, and repeatability of the gas recombination rate. To further improve recombination performance, methods to increase the catalyst surface area, hydrophobicity, and availability were developed and evaluated. Of these, including in the electrolyte pyrolyzed-Nafion ${ }^{\circledR}$-coated $\mathrm{Pt}$ segments contained in the actuator chamber accelerated recombination by increasing the catalyst surface area and decreasing the gas transport diffusion path. This approach also reduced variability in recombination encountered under varying actuator orientation (resulting in differing catalyst/gas bubble proximity) and increased the rate of recombination by 2.3 times across all actuator orientations. Repeatability of complete recombination for different generated gas volumes was studied through cycling.
\end{abstract}

Index Terms - Electrolysis microactuators, gas recombination 


\section{INTRODUCTION}

Water electrolysis is possibly the oldest known example of direct conversion of electrical energy to pressure/volume changes [1, 2]. In 1839, William Grove discovered that operating electrolysis in reverse can produce water and electricity by combining hydrogen and oxygen. Since then, electrolysis and recombination have been extensively studied and widely employed in actuators and fuel cells. Electrolysis has been used in a variety of applications (e.g. electrometallurgy, anodization, oxygen and hydrogen production, etc.) and even miniaturized in electrochemical actuators suitable for a variety of interesting biological, chemical, and medical applications [3]. Advances in bio-microelectromechanical (MEMS) techniques and polymer micromachining have produced innovative electrolysis-based actuators and a renewed interest for implantable pump applications with unique packaging and performance [4]. Electrochemically driven microactuators feature low power consumption, low heat dissipation, large displacement (hundreds of microns), and smooth continuous flow, making them an attractive choice over other methods [5-8]. These characteristics enable precision pumping [9-11] which have been leveraged for ocular drug delivery [3, 12], gene delivery in cancer treatment [13], and experimental drug delivery paradigms for small animals $[14,15]$.

A key factor in the operation efficiency of both electrolysis actuators and fuel cells is the speed and efficiency of the recombination of generated gases. For unitized regenerative fuel cells, this reaction directly affects the efficiency of electric power generation. In electrolysis actuators, speed of recombination determines how quickly the generated gases can be reset to an all-liquid state. The recombination reaction is limited by the requisite high overpotentials and activation energy [16]. In typical devices, electrolysis and recombination occur in the same chamber, and therefore catalysts suitable for precipitating both forward and reverse reactions are the preferred material of choice for electrodes [17]. Platinum (Pt) has this capability and is thus commonly selected as the catalytic electrode material. In larger devices, due to the high cost of Pt, the electrodes are replaced with carbon-based material. However, a significant drawback of this replacement is that the carbon-based electrodes are corroded under oxygen evolution during electrolysis [18]. The challenge in choosing the appropriate catalyst lies in the competing requirements for electrolysis and recombination. During electrolysis, a hydrophilic catalytic surface is required. However, during recombination, hydrophilicity causes flooding of the electrocatalyst and the gases are repelled [17, 19]. Therefore, during the recombination phase, a more hydrophobic catalytic surface is desired to encourage the gases to contact the catalytic surface and recombine into water.

Solid polymer electrolytes, such as Nafion ${ }^{\circ}$, in addition to or instead of water, can be used to achieve balanced hydrophilic/hydrophobic properties that could aid in recombination without having detrimental 
effects on electrolysis [19-21]. Alternatively, the Pt catalyst composition can be modified with the addition iridium or carbon $[21,22]$. The separation of gases during electrolysis and their controlled release during the recombination phase has also been explored [9, 23].

In order to incorporate strategies to accelerate recombination in microactuators, several design factors including size, materials, fabrication methods, and complexity need be considered as they may have a significant effect on the reliability and repeatability of operation. For this work, the end goal is to develop microactuators for medical applications, hence biocompatibility concerns and size restrictions limit the selection of materials for the actuator and electrocatalyst.

Electrolysis-based microactuators have the potential to be useful in applications requiring controlled sitespecific drug delivery [24-26]. Recombination characterization of uncoated and Nafion ${ }^{\circledR}$-coated $\mathrm{Pt}$ microactuator electrodes in a $3 \mathrm{~mL}$ testing chamber on the basis of displaced electrolyte volume was previously reported in [25]. The recombination volume was observed to increase monotonically with gas volume generated by electrolysis. The higher solubility of gases in Nafion ${ }^{\circledR}$ facilitated diffusion of gases to the electrode surface and may have produced a concentration gradient that further drived diffusion; therefore, recombination rate was higher in Nafion ${ }^{\circledR}$-coated compared to uncoated electrodes. Here, in order to add the reliability and repeatability of microactuator operation which are critical in controlling drug delivery, different approaches to accelerate recombination including the limitation of chamber size (by including a Parylene bellows), increase in catalytic surface area, and altering the hydrophobicity of the catalytic surface were investigated. Recombination rate was also examined for changes in device orientation, to replicate conditions that may be found in implantable drug pumps relying on electrolysis for actuation. Lastly, repeatability of complete recombination was studied through cycling (actuation followed by recombination).

\section{TheORETICAL CONSIDERATIONS}

\subsection{Electrolysis and Recombination}

Electrolysis is initiated when a sufficient potential or current is applied to a pair of electrodes in contact with an electrolyte (water). The reaction induces water dissociation into oxygen and hydrogen gas An important factor in electrolysis efficiency (defined as the ratio of experimentally generated gas volume the theoretically calculated gas volume) is availability of water at the catalyst surface, thus, a hydrophilic catalyst surface is preferred for electrolysis [27].

After the driving voltage or current used to induce electrolysis is removed, generated gases begin to recombine into liquid water. At the anode, hydrogen is oxidized, while at the cathode, oxygen is reduced. 
As a result, the overall reaction is the oxidation of hydrogen by oxygen to form water [28]. This reaction requires the strong double bond of molecular oxygen to be broken first, and as a result, it is limited by high overpotentials and activation energy $(\sim 400 \mathrm{mV})$ [29]. Recombination rate is subject to the slow diffusion of $\mathrm{O}_{2}$ and $\mathrm{H}_{2}$ through the electrolyte to the surface of the Pt catalyst. The diffusion distance is affected by the ratio of gas to liquid inside the electrolysis chamber [23] and the orientation and volume of the chamber in which the reaction is conducted. At the surface of the catalyst, the presence of water could cause flooding, preventing gas contact with the catalyst, which is detrimental to recombination efficiency. Thus, a hydrophobic catalyst surface is preferred for recombination [27].

\subsection{Nafion ${ }^{\circledR}$}

Nafion ${ }^{\circledR}$ is an ionomer developed by Dr. Walther Grot at DuPont in the late 1960's [30]. The polymer has a perfluorinated backbone and short pendant chains terminated by a sulfonic head group. The sulfonic acid groups cluster to form a hydrophilic microphase surrounded by a hydrophobic tetrafluoroethylene backbone. It has been shown that Nafion ${ }^{\circledR}$ undergoes molecular rearrangement at the polymer-fluid/gas interface to minimize surface energy. When the ionomer is exposed to liquid water, the hydrophilic sulfonic acid groups are drawn to the surface, and surface energy is minimized by presenting the hydrophobic backbone to a gas interface [31]. Nafion ${ }^{\circledR}$ also possesses high gas solubility (solubility of $\mathrm{O}_{2}$ and $\mathrm{H}_{2}$ is 1.8 times higher in Nafion ${ }^{\circledR}$ compared to water; $\mathrm{O}_{2}$ solubility is $7.2 \times 10-6 \mathrm{~mol} . \mathrm{cm}^{-3}$ in hydrated $\mathrm{Nafion} \AA[42]$ and $0.26 \times 10^{-6}$ mol.cm ${ }^{-3}[43]$ in water and $\mathrm{H}_{2}$ solubility is $1.4 \times 10^{-6}$ mol.cm ${ }^{-3}$ in hydrated Nafion ${ }^{\circledR}$ and $0.78 \times 10^{-6}$ mol.cm ${ }^{-3}$ in water [38]). Faster gas diffusion can aid in recombination by facilitating transport of gases to the catalyst surface. It is important to note however, that alkali metals (particularly sodium) can attack Nafion ${ }^{\circledR}$ directly under normal conditions of temperature and pressure, therefore when used as a solid polymer electrolyte, it is best to hydrate it with water rather than saline [30].

\subsection{Accelerating Recombination}

Recombination rate is a function of three factors: transport of gas through the electrolyte to the surface of the catalyst, ratio of gas to liquid inside the reaction chamber (e.g. volume of gas generated during the actuation period), and the size of the chamber. Gas recombination occurs in two phases. The rate is diffusion limited while bubbles are diffusing through electrolyte to the surface of the catalyst but once a sufficient volume of gas bubbles are available at the surface of the catalyst, the recombination becomes reaction limited [44]. Hydrophilicity at the surface of the catalyst causes flooding of the electrocatalyst and the gases are repelled [21, 23], leading to slower recombination. 
As such, the rate of recombination can be increased by decreasing the diffusion path through the electrolyte to the surface of the catalyst or increasing the rate of gas transport through the electrolyte, increasing the available catalyst surface area, and increasing the hydrophobicity of the catalyst surface.

\section{DESIGN AND FABRICATION}

Interdigitated Pt electrodes (100 $\mu \mathrm{m}$ wide elements separated by $100 \mu \mathrm{m}$ gaps, $8 \mathrm{~mm}$ diameter footprint) were fabricated on Borofloat ${ }^{\circledR} 33$ glass wafers (University Wafer, Boston, MA) by a liftoff method similar to the process described in [26]. Briefly, a dual-layer photoresist process was used to create an undercut sidewall profile to facilitate metal liftoff. First, AZ1518 photoresist (AZ Electronic Materials, Branchburg, $\mathrm{NJ}$ ) was spun at $4 \mathrm{krpm}$ followed by global exposure ( thickness $1.8 \mu \mathrm{m})$. Then, AZ4400 photoresist (AZ Electronic Materials, Branchburg, NJ) was applied at $4 \mathrm{krpm}$ and patterned ( $\sim$ thickness $4 \mu \mathrm{m})$. Following a short descum in oxygen plasma, a Ti/Pt film (300 $\AA / 2000 \AA)$ was e-beam evaporated and then liftoff was performed. Finally, individual dies were separated using resin blade dicing saw (Disco DAD-2H/6, Giorgio Technologies, Mesa, AZ).

Prior to Nafion ${ }^{\circledR}$ coating, electrodes were potentiostatically cleaned at $\pm 0.5 \mathrm{~V}$ (Gamry Reference 600 Potentiostat, Warminster, PA) in $1 \times$ phosphate buffered saline (PBS) and then rinsed with double distilled (DD) water. Nafion ${ }^{\circledR}$ (Dupont DE521 Solution, Ion Power, INC, New Castle, DE) was applied to the electrodes by dip coating twice. Each coating layer was cured at $60{ }^{\circ} \mathrm{C}$ for 5 minutes. Kynar ${ }^{\mathrm{TM}}$ silver plated copper wires (30 AWG, Jameco Electronics, Belmont, CA) were soldered to contact pads on the electrodes. The joint was strengthened and insulated with nonconductive marine epoxy (Loctite, Westlake, $\mathrm{OH}$ ).

The microactuator consists of an electrolyte-filled chamber formed by a Parylene bellows and rigid substrate supporting a pair of electrodes. For pumping applications such as drug delivery, the bellows is contained within a fluid reservoir. A bellows membrane was chosen to limit the size of the electrolysis chamber, contain the electrolysis gases, and prevent electrochemical interaction with the drug solution during actuation [15]. The bellows shape allows for greater achievable deflections at lower applied pressures compared to a corrugated or flat diaphragm [3]. Volume expansion as a result of water electrolysis inflates the bellows, which in turn acts on the fluid column above it, leading to fluid displacement from a drug reservoir through a catheter to the target delivery site. For this system, recombination is an important factor for reliable and repeatable delivery, as it determines how fast the system is reset (return of bellows to starting position in the unactuated state) following delivery, as well as the number of doses that can be safely delivered without damaging the bellows structure, prior to resetting (Figure 1). 


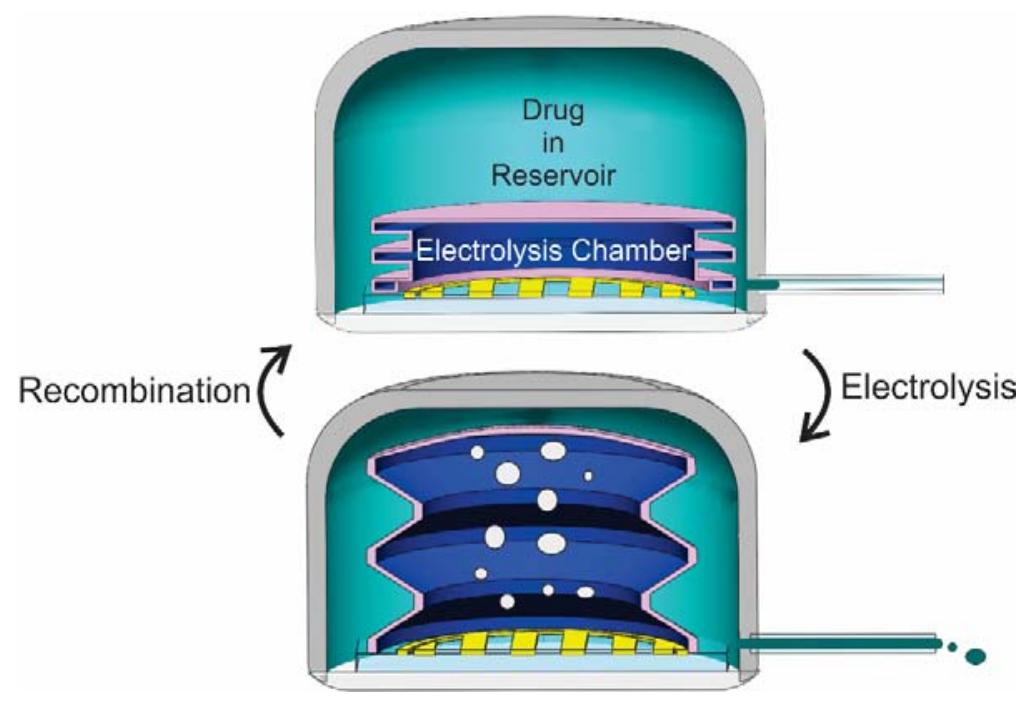

Figure 1: Operation concept for electrolysis microactuator developed as part of a micropump system for controlled site-specific drug delivery.

\section{EXPERIMENTAL METHODS}

\subsection{Limiting Chamber Size}

In order to contain the electrolysis and recombination reaction and limit the size of the chamber, Parylene bellows were fabricated as described in [32] and combined with Nafion ${ }^{\circ}$-coated electrodes to create bellows actuators [25]. The bellows allow for large (up to $180 \mu \mathrm{L}$ ) volume displacement without undergoing plastic deformation compared to flat or corrugated diaphragms. Recombination of $145 \mu \mathrm{L}(80 \%$ of maximum allowable volume chosen as a safety margin to prevent irreversible plastic deformation to the bellows during electrolysis actuation) of electrolysis generated gas was observed for one hour and compared to results obtained for a similar volume of gas generated and recombined in the $3 \mathrm{~mL}$ acrylic test fixture.

\subsection{Improving Recombination Efficiency}

Several methods were explored to improve the recombination rate in a bellows actuator (Table 1). In each case, the prepared actuator was clamped in a $3 \mathrm{~mL}$ acrylic test fixture and filled with DD water. The outlet of the test fixture was attached to a $100 \mu \mathrm{L}$ micropipette. Generated gas volume and recombination was indirectly measured by observing the fluid front movement in the micropipette. $2 \mathrm{~mA}$ current was applied to the actuator until $4 \mathrm{~mm}$ of movement was observed in the micropipette $(5.33 \mu \mathrm{L}$ of gas generated). The current was turned off and recombination was measured based on the fluid back flow in the micropipette. The fluid meniscus position was recorded periodically for 60 minutes or until the entire bolus had recombined, whichever came first. 
Table 1: Visual depiction of different modification techniques employed to accelerate recombination and their acceleration concept.

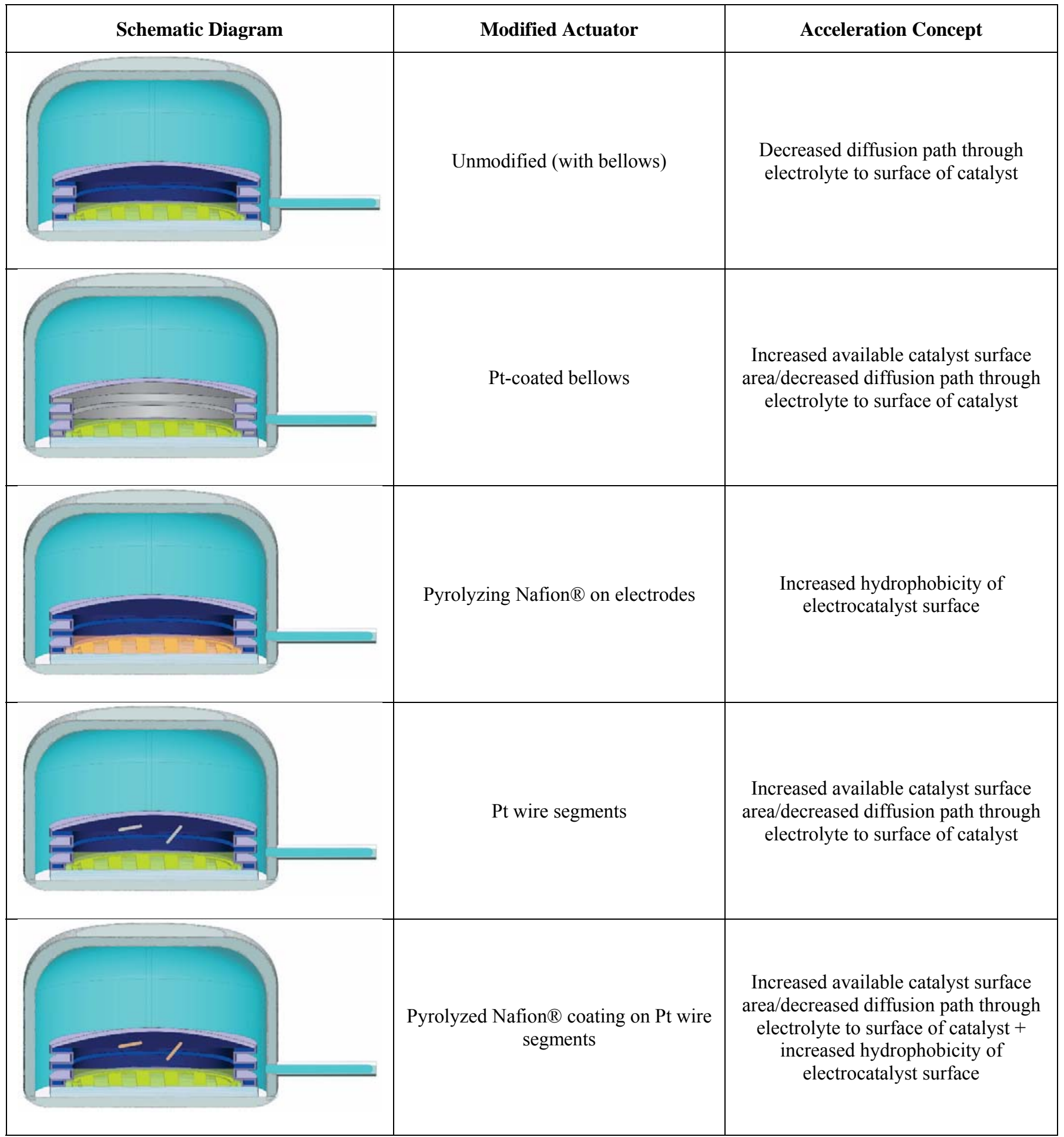

4.2.1. Pt-coated bellows: The inside surfaces of the Parylene bellows were coated with $1800 \AA$ layer of Pt using e-beam evaporation. Three samples were prepared. Two of these were then further coated in a thin layer of Nafion ${ }^{\circledR}$, one of which was cured at $60{ }^{\circ} \mathrm{C}(1)$ and the other at 
room temperature (2). The bellows were each filled with DD water and then combined with a Nafion ${ }^{\circledR}$-coated electrode to form actuators (one device was fabricated from each of the samples).

4.2.2. Pyrolyzing Nafion ${ }^{\circledR}$ on electrodes: As previously mentioned, Nafion ${ }^{\circledR}$ has a perfluorinated backbone and short pendant chains terminated by sulfonic head group. If the polymer is heated to between $280-320^{\circ} \mathrm{C}$, a small portion of the Nafion ${ }^{\circledR}$ pyrolyzes to lose the sulfonic acid groups. These portions are hydrophobic and repel water, however they allow the passage of gases. Zhang et. al., explored this phenomena to increase the efficiency of their proton exchange membrane (PEM) fuel cell in [22]. The group found that at temperatures below 300 ${ }^{\circ} \mathrm{C}$, pyrolysis was insufficient; however, at temperatures above $340{ }^{\circ} \mathrm{C}$, the hydrophobicity inversely affected electrolysis efficiency. Based on this information, the Nafion $®$-coated electrolysis electrodes were heat treated at $320^{\circ} \mathrm{C}$ under $\mathrm{N}_{2}$ backflow for an hour, then slowly cooled to room temperature. To further improve the adhesion between the pyrolyzed Nafion ${ }^{\circledR}$ and the Pt electrode, a thin layer of Nafion ${ }^{\circledR}$ was applied to the surface and cured at room temperature. The electrode was then combined with a water filled bellows ( 2 devices were).

4.2.3. Pt wire segments: An alternate placement for the Pt catalyst is within the electrolyte solution itself. To accomplish this, two $3 \mathrm{~mm}$ segments of 99.9\% Pt wire (Ø $0.5 \mathrm{~mm})$ (California Fine Wire, Grover Beach, CA) were selected. The edges of the wire were smoothed using 220 grit silicon carbide sandpaper. The segments were suspended in the DD water filled bellows, before the bellows were affixed to electrodes ( 2 devices were fabricated).

4.2.4. Pyrolyzed Nafion ${ }^{\circledR}$ coating on Pt wire segments: Another two $3 \mathrm{~mm}$ segments of $99.9 \% \mathrm{Pt}$ wire (Ø $0.5 \mathrm{~mm}$ ) (California Fine Wire, Grover Beach, CA) were selected. The edges of the wire were smoothed using 220 grit silicon carbide sandpaper. The segments were then coated with Nafion ${ }^{\circledR}$ and heat treated at $320{ }^{\circ} \mathrm{C}$ under $\mathrm{N}_{2}$ backflow for an hour, then slowly cooled to room temperature. The pyrolyzed- Nafion ${ }^{\circledR}$-coated segments were suspended in the DD water filled bellows, before the bellows were affixed to electrodes ( 3 devices were fabricated). 


\subsection{Orientation Dependency}

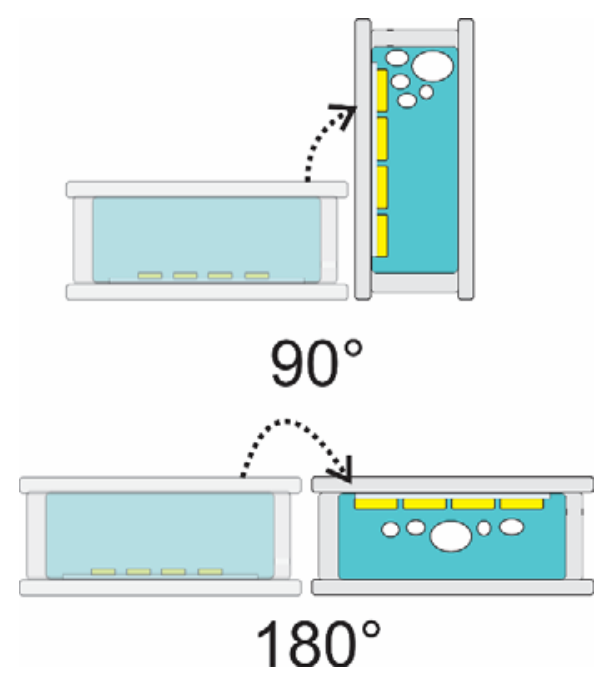

Figure 2: The angle of an actuator clamped in a test fixture was varied for each volume $\left(0^{\circ}\right.$, actuator facing up on the benchtop, $90^{\circ}$, actuator perpendicular to benchtop, and $180^{\circ}$, actuator facing down on the benchtop).

For the above experiments, gas recombination was characterized with the electrode clamped in the test fixture and placed facing up on the benchtop such that the generated gases rose up away from the electrode. However, for some applications, it is desired and sometimes inevitable for the actuator, and therefore electrodes, to assume other orientations. For instance, the electrolysis actuator may be used in an implanted pump which may be placed at a different orientation or change in position within the subject. Therefore, recombination dependence on actuator orientation was also tested with unmodified actuators with Nafion ${ }^{\circledR}$ coated electrode catalyst (henceforth referred to as unmodified), as well as actuators with additional pyrolyzed Nafion ${ }^{\circledR}$ coating on suspended Pt wire segments. Several current and time combinations were applied to the actuator to achieve different generated gas volumes of $0.277,1.11,5.33,10,25.33$, and 50 $\mu \mathrm{L}$. The angle of an actuator clamped in a test fixture was varied for each volume (Figure 2; $0^{\circ}$, actuator facing up on the benchtop, $90^{\circ}$, actuator perpendicular to benchtop, and $180^{\circ}$, actuator facing down on the benchtop). Recombination was monitored until the entire delivered volume was recombined or for an hour, whichever came first.

\subsection{Repeated Cycling}

For a microactuator, speed of recombination determines how quickly the generated gases can be reset to an all-liquid state. As such, repeatable and reliable microactuator operation is dependent on repeatable complete recombination. Incomplete recombination could lead to lower and inconsistent delivery actuation flow rates as the bellows structures approaches maximum deflection. Further inflation as a result of electrolysis could result in permanent deformation of the bellows via plastic deformation [33]. For instance, Figure 3 demonstrates an example where three $10 \mu \mathrm{L}$ gas boluses are generated and allowed to recombine 
for 30 minutes between each bolus generation. Then, following a waiting period for further recombination to partially reset the bellows, four $50 \mu \mathrm{L}$ gas boluses are generated and allowed to recombine for 60 minutes between each bolus generation (data based on electrolysis and recombination observed for an unmodified actuator). If the wait time between the first set of boluses and the initiation of the second set is not sufficient for full recombination, the fourth $50 \mu \mathrm{L}$ gas bolus generated would cause the bellows to exceed maximum deflection ( $>180 \mu \mathrm{L}$ delivered). The wait time is dependent on the speed of recombination, as well as repeatability of recombination for a specific bolus volume. Therefore, it is important to study the repeatability of recombination of generated gas volumes through repeated cycling for applications such as implantable pumps in which reliable and accurate performance of the actuator driving drug dosing is critical.

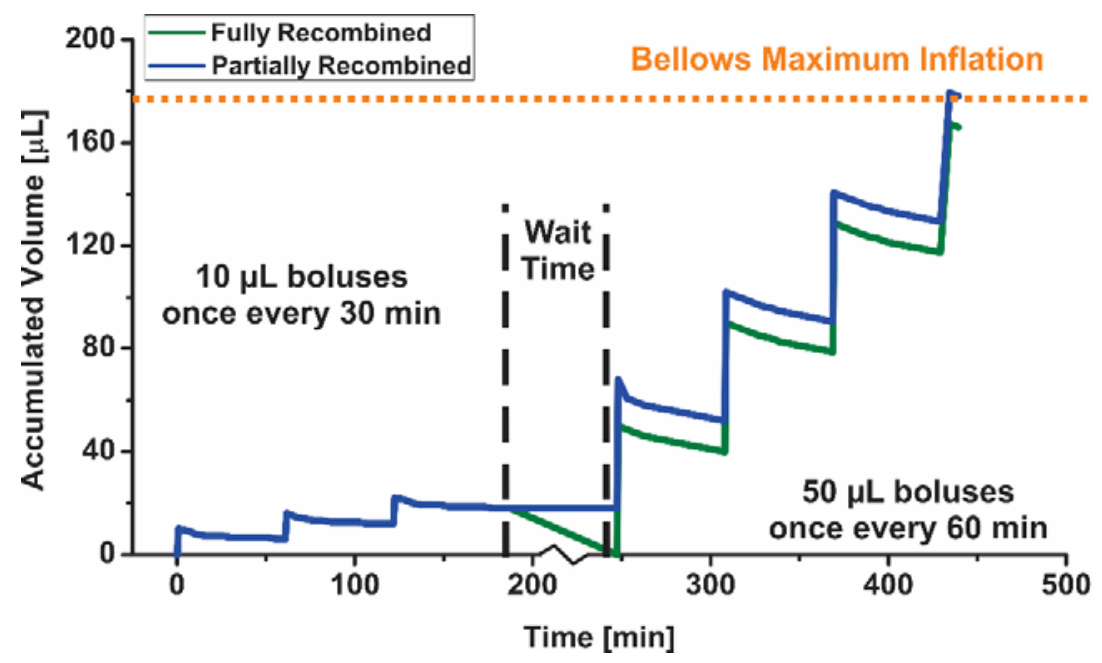

Figure 3: Hypothetical example: if the wait time (denoted with dashed vertical lines) between the first and second set of generated gas boluses (10 and $50 \mu \mathrm{L}$, respectively) is not sufficient for complete recombination, the bellows structure will exceed maximum inflation when the fourth $50 \mu \mathrm{L}$ bolus is generated).

An actuator was assembled having unmodified Nafion ${ }^{\circledR}$-coated electrodes and suspended Pt wire segments with pyrolyzed Nafion ${ }^{\circledR}$ coating and then clamped in a $3 \mathrm{~mL}$ acrylic test fixture. The reservoir was filled with DD water and a $100 \mu \mathrm{L}$ micropipette was attached to the outlet of the test fixture. Generated gas volume and recombination were indirectly measured by observing the movement of the fluid meniscus along the micropipette. $2 \mathrm{~mA}$ current was applied to the actuator until $7.5 \mathrm{~mm}$ of movement was observed in the micropipette (corresponding to $10 \mu \mathrm{L}$ of gas generated). The current was turned off halting electrolysis and recombination was measured based on the fluid back flow in the micropipette. The fluid meniscus position was recorded periodically until the entire bolus had recombined, at which time another $10 \mu \mathrm{L}$ of gas generated and the recombination monitored. After 24 hours, three $5 \mu \mathrm{L}$, followed by three 10 $\mu \mathrm{L}$ boluses of gas were generated. Full recombination of each generated bolus was monitored and recorded. 


\section{EXPERIMENTAL RESULTS AND DISCUSSION}

\subsection{Limiting Chamber Size}

When the Parylene bellows were combined with Nafion ${ }^{\circledR}$-coated electrodes, recombination followed a predictable non-linear diffusion dependent pattern and $99.08 \%$ recombination was achieved within 1 hour of delivery (data not shown). This is considerably larger than the fraction of gas recovered in the larger volume using the same electrodes in the same time period. As previously mentioned, slow diffusion of gas bubbles through the electrolyte was a determining factor in the rate of recombination. By limiting the chamber volume, the diffusion path was limited, leading to faster recombination.

\subsection{Improving Recombination Efficiency}

The recombination performance over time for the different methods explored are presented in Figure 4 and detailed in Table 2. The lowest rate of recombination was observed for unmodified actuators with Nafion ${ }^{\circledR}$-coated electrodes, while the highest rate was observed for actuators with pyrolyzed Nafion ${ }^{\circledR}$ coated electrodes. Recombination rate was seen to increase for bellows coated internally with thin films of $\mathrm{Pt}$ and Nafion ${ }^{\circledR}$-coated Pt. It is important to note that the recombination rate was faster for the actuator with Nafion ${ }^{\circledR}$-coated Pt-coated bellows (1), for which the Nafion ${ }^{\circledR}$ coating was cured at $60{ }^{\circ} \mathrm{C}$ compared to the other cured at room temperature (2). This is likely due to the slight increase in surface hydrophobicity as a result of heat application to the Nafion ${ }^{\circledR}$. Suspended Pt wire segments (coated and uncoated) produced faster rated of recombination than unmodified actuators, but noticeably lower rates than actuators with pyrolyzed Nafion ${ }^{\circledR}$-coated electrodes.

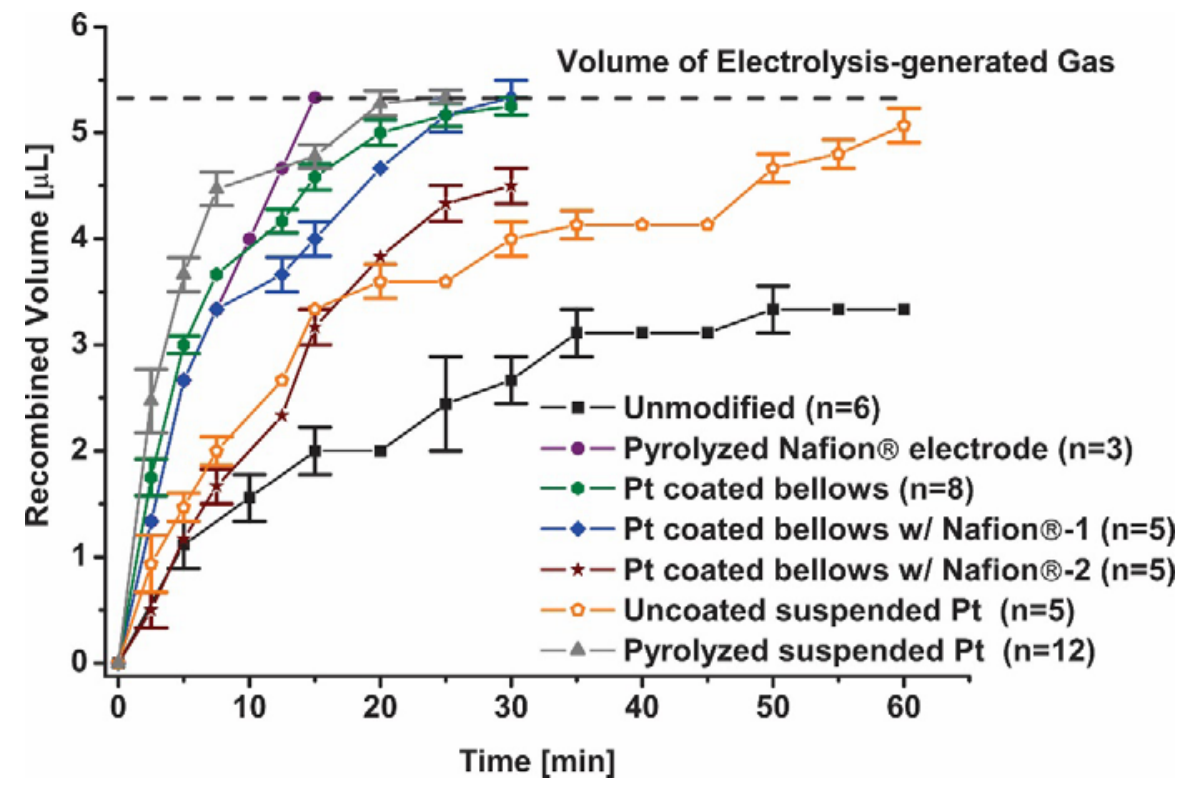

Figure 4: Recombination time course for a $5.33 \mu \mathrm{L}$ bolus delivered with actuators fabricated utilizing different methods to accelerate recombination. 
Table 2: Recombination time course expressed as \% recombined for a $5.33 \mu \mathrm{L}$ bolus was delivered with actuators fabricated utilizing different methods to accelerate recombination.

\begin{tabular}{|c|c|c|c|c|c|c|c|}
\hline \multirow[b]{2}{*}{$\begin{array}{l}\text { Time } \\
\text { [min] }\end{array}$} & \multicolumn{7}{|c|}{$\%$ Recombined } \\
\hline & Unmodified & $\begin{array}{c}\text { Pyrolyzed } \\
\text { Nafion } \AA \\
\text { Electrode }\end{array}$ & $\begin{array}{l}\text { Pt Coated } \\
\text { Bellows }\end{array}$ & $\begin{array}{c}\text { Pt Coated } \\
\text { Bellows } \\
\text { W/Nafion }{ }^{\circledR} \\
\text { (1) }\end{array}$ & $\begin{array}{l}\text { Pt Coated } \\
\text { Bellows } \\
\text { W/Nafion }{ }^{\circledR} \\
\text { (2) }\end{array}$ & $\begin{array}{c}\text { Uncoated } \\
\text { Suspended } \\
\mathrm{Pt}\end{array}$ & $\begin{array}{c}\text { Pyrolyzed } \\
\text { Suspended } \\
\text { Pt }\end{array}$ \\
\hline 15 & 37.52 & 100 & 85.93 & 75.04 & 59.48 & 62.48 & 89.63 \\
\hline 25 & 45.86 & - & 96.93 & 96.93 & 81.3 & 67.54 & 100 \\
\hline 30 & 50.09 & - & 100 & 100 & 84.43 & 75.05 & - \\
\hline 35 & 58.35 & - & - & - & 93.81 & 77.49 & - \\
\hline 60 & 62.54 & - & - & - & - & 95.12 & - \\
\hline
\end{tabular}

For Pt-coated bellows, in all cases, the Pt delaminated from the surface of the Parylene over time likely due to the exposure to the generated bubbles and the stress caused by the inflation of the bellows structure during actuation. Delamination may have been facilitated by the presence of exposed metal interfaces that arise as the deposition technique is unable to completely coat the convolutions in the bellows. This delamination did not affect electrolysis or recombination during testing. However, given the unreliable adhesion between the Parylene and $\mathrm{Pt}$, this method cannot be used to maintain a constant catalyst surface area. The electrodes with the pyrolyzed Nafion ${ }^{\circledR}$ coating showed the fastest recombination rate $(2$ devices fabricated). However, despite the additional overcoat layer of Nafion ${ }^{\circledR}$, the pyrolyzed layer delaminated from the surface of the electrode during electrolysis and therefore repeatable results $(n>4)$ could not be obtained using this method. Consistent performance was observed in actuators with the pyrolyzed Nafion ${ }^{\circledR}$-coated segments (in the three devices fabricated). The catalyst segments in the water did not affect electrolysis gas generation. The modification methods were intended to accelerate recombination by either increasing the catalyst surface area, increasing the catalyst surface hydrophobicity, or increasing the rate of gas transport. Adding pyrolyzed-Nafion ${ }^{\circledR}$-coated Pt segments in the actuator achieves all three functions by providing more catalyst surface area, utilizing a hydrophobic coating attractive to gas bubbles, and situating catalyst throughout the electrolysis chamber.

\subsection{Orientation Dependency}

Contrary to the results obtained for actuation [26], there is a clear distinction, between recombination speed and the angle of the actuation chamber for a given generated gas volume for unmodified actuators with Nafion ${ }^{\circledR}$-coated electrode catalyst. Figure 5 displays fraction of recombined gas for devices with unmodified and suspended pyrolyzed-Nafion ${ }^{\circledR}$-coated Pt segments at each tested orientation $\left(0^{\circ}, 90^{\circ}\right.$ and $\left.180^{\circ}\right)$. The highest fraction of recombined gas volume was observed for both electrode designs in the $180^{\circ}$ orientation. For both actuator designs greater recombination was observed for $90^{\circ}$ than $0^{\circ}$ orientations, however the performance difference between the two orientations was comparatively small. The actuator 
with suspended pyrolyzed-Nafion ${ }^{\circledR}$-coated $\mathrm{Pt}$ segments produced greater recombination than the unmodified design, and the variation in performance as a function of orientation was considerably reduced. On average, the rate of recombination was measured to be 2.3 times faster across all actuator orientations ( $\mathrm{n}=3$ for each dose volume at each orientation).

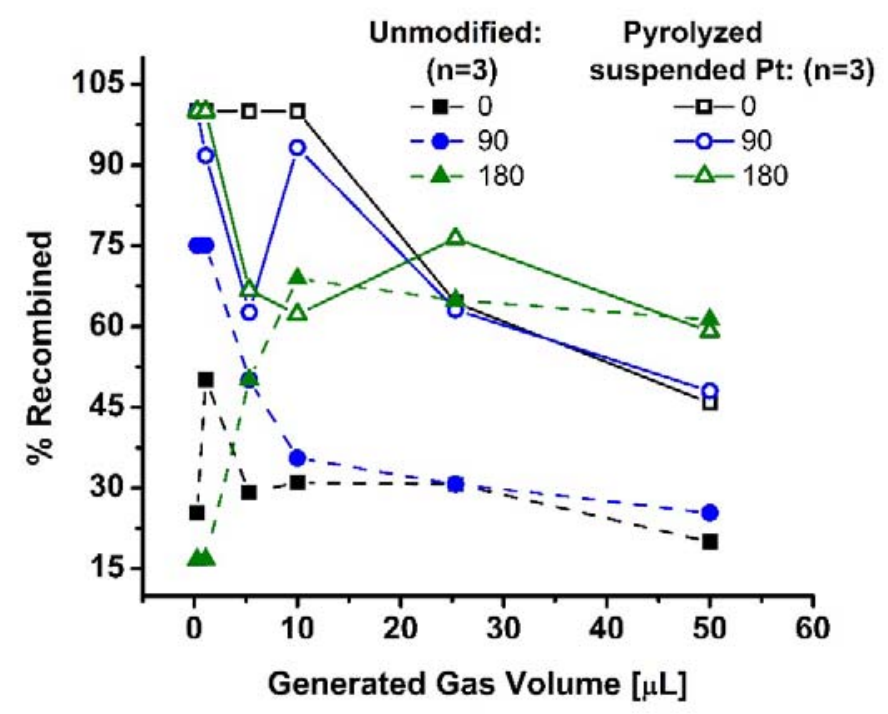

Figure 5: \% Recombination vs. angular orientation for different delivered generated gas volumes for unmodified actuators with Nafion ${ }^{\circledR}-c o a t e d$ electrode catalyst and actuators with additional pyrolyzed Nafion ${ }^{\circledR}$ coating on suspended Pt wire segments.

These observations can be explained by the behavior of the electrolyzed gas under the influence of the buoyant force. Gas bubbles created during electrolysis tend to travel upwards within the test fixture; after the current application is discontinued, the bubbles need to reach the surface of the Pt catalyst to recombine; the reaction is limited by the slow diffusion of gases through water. In the $90^{\circ}$ and $180^{\circ}$ orientations, the bubbles are in contact with the catalyst as soon as the current application is halted. As a result, recombination rate is increased in these orientations. By the same reasoning, the $180^{\circ}$ orientation is faster than $90^{\circ}$ due a larger catalyst surface area available to assist recombination. The effects of orientation were reduced for actuators with additional pyrolyzed-Nafion ${ }^{\circledR}$ coating on Pt wire segments. 


\subsection{Repeated Cycling}
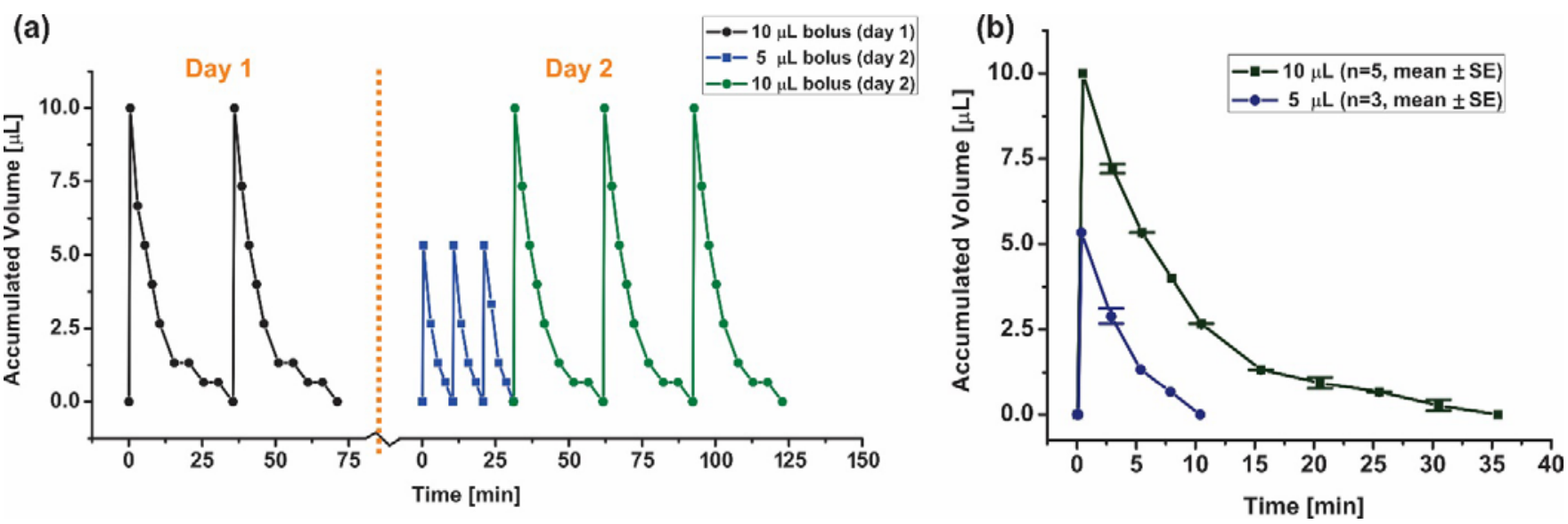

Figure 6: (a) Repeated cycling (actuation and recombination), (b) averaged trends for actuation and recombination of for 10 and 5 $\mu L$ boluses.

Figure 6 shows the results of repeated cycling (actuation and recombination) for 10 and $5 \mu \mathrm{L}$ boluses. Repeatable complete recombination was achieved for consecutive gas bolus volumes generated as well as boluses delivered after 24 hours idle time. Figure 7 illustrates actuation and recombination results obtained for different generated gas volumes of $0.277,1.11,5.33,10,25.33$, and $50 \mu \mathrm{L}$ for an actuator facing up on the benchtop ( $n=3$, obtained for orientation dependency testing). The average time required for complete recombination of each of the generated gas volumes is presented in Table 3. An exponential trend line was fit to the data for 25.33 and $50 \mu \mathrm{L}$ volumes to estimate the time required for complete recombination of the generated gas volumes. As demonstrated previously in the orientation dependency section, recombination is slowest when the actuator is placed facing up on the benchtop. Therefore, these recombination profile results obtained for different generated gas volumes can be used to estimate the rate of recombination and the maximum allotted wait time required for complete recombination of generated gases. It is important to note that changing the orientation of the actuator, as well as generation of large gas boluses $(>25 \mu \mathrm{L})$ leading to significant inflation of the bellows, could cause the repositioning of the pyrolyzed-Nafion ${ }^{\circledR}$ coated Pt wire segments, which may slightly alter the recombination time profile. These variations are represented by the error bars in Figures 4 and 7. 

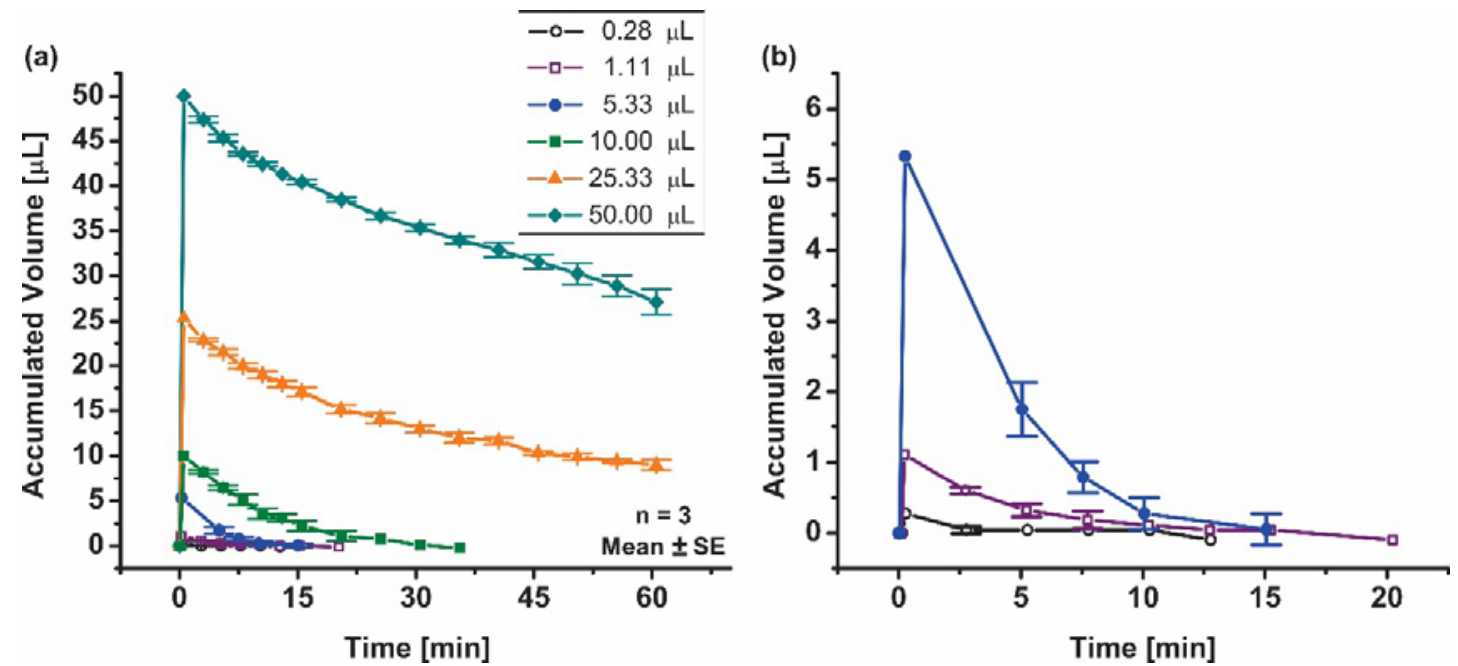

Figure 7: (a) Actuation and recombination results obtained for different generated gas volumes of 0.277, 1.11, 5.33, 10, 25.33, and $50 \mu \mathrm{L}$ for an actuator facing up on the benchtop. (b) Data for smaller bolus volumes.

Table 3: Average time required for complete recombination of different generated gas volumes.

\begin{tabular}{|c|c|c|c|c|c|c|}
\hline Time Required & \multicolumn{7}{|c|}{ Generated Gas Volume $[\mu \mathrm{L}]$} \\
\cline { 2 - 7 } $\begin{array}{c}\text { for Complete } \\
\text { Recombination } \\
{\left[\begin{array}{c}\text { [min] }\end{array}\right.}\end{array}$ & 0.277 & 1.11 & 5.33 & 10 & 25.33 & 50 \\
\cline { 2 - 7 } & 12.75 & 20 & 15 & 36 & 300 & 450 \\
\hline
\end{tabular}

\section{CONCLUSION}

Electrolysis and recombination have been extensively studied and utilized in actuators and unitized regenerative fuel cells. Speed and efficiency of gas recombination is a key factor in the operation efficiency of both electrolysis actuators and fuel cells. Recombination rate is a function of three factors: transport of gas through the electrolyte to the surface of the catalyst, ratio of gas to liquid inside the reaction chamber (e.g. volume of gas generated during the actuation period), and the size of the chamber. The challenge in choosing the appropriate catalyst lies in the competing requirements for electrolysis and recombination. During electrolysis, a hydrophilic catalytic surface is required. However, during the recombination phase, a more hydrophobic catalytic surface is desired to encourage the gases to contact the catalytic surface and recombine into water.

Several methods of improving recombination speed and repeatability were considered. Previous studies had shown that coating of the electrolysis electrodes in Nafion ${ }^{\circledR}$ resulted in faster and more consistent recombination [25]. This is attributed to physical and chemical properties of the polymer, including the higher solubility of oxygen and hydrogen, as well as, undergoing molecular rearrangement at the polymerfluid/gas interface to minimize surface energy, and therefore presenting the appropriate hydrophilic/hydrophobic surface during actuation/recombination, respectively. Here, first, the size of the electrolysis chamber was decreased to limit the diffusion path leading to faster, predictable non-linear 
diffusion dependent recombination. Pyrolysis of the Nafion ${ }^{\circledR}$ coating on the electrolysis electrodes, resulted in the highest recombination rate as it increased the hydrophobicity of the catalyst surface. However, the pyrolyzed layer delaminated from the surface of the electrode during electrolysis and therefore repeatable results $(n>4)$ could not be obtained using this method. The addition of pyrolyzed-

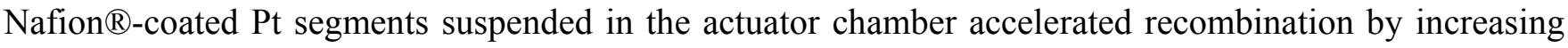
the catalyst surface area and hydrophobicity, as well as decreasing the gas transport diffusion path. This modification method also reduced the effects of actuator orientation (resulting in differing catalyst/gas bubble proximity) on recombination. On average, the rate of recombination was measured to be 2.3 times faster across all actuator orientations. Repeatable cycling results were also obtained for this modification method. These improvements in recombination rates have significant implications for electrolytic microactuators. Faster, more consistent recombination leads to reliable and repeatable actuations, as it determines how fast the system is reset following actuation, as well as the number of actuations that can be safely carried out prior to resetting. In particular these demonstrated modifications have relevance to devices intended for biological implantation, as preserving performance for a variety of orientations is critical for such applications. It is important to note that while the methods presented here are applied to a microactuator, they can be similarly applied to electric power generation in micro-unitized regenerative fuel cells, and other applications of electrolysis in microscale devices.

\section{ACKNOWLEDGMENT}

This work was funded in part by NSF through the PFI: AIR Technology Translation program (award number IIP-1343467) and NIH (award number R21GM104583) funding sources. The authors would like to thank Drs. C. A. Gutierrez, S. Hara, and K.W. Scholten and the members of the USC Biomedical Microsystems Laboratory for their assistance. Ellis Meng has a significant financial interest in Fluid Synchrony LLC.

\section{REFERENCES}

[1] M. Faraday, "Proceedings of the Royal Society of London," Philosophical Transactions of the Royal Society of London, vol. 124, pp. 77-122, 1834.

[2] W. Nicholson, A Journal of natural philosophy, chemistry and the arts: G. G. and J. Robinson, 1800.

[3] P.-Y. Li, R. Sheybani, C. A. Gutierrez, J. T. W. Kuo, and E. Meng, "A parylene bellows electrochemical actuator," Journal of Microelectromechanical Systems, vol. 19, pp. 215-28, 2010.

[4] E. Meng and T. Hoang, "MEMS-enabled implantable drug infusion pumps for laboratory animal research, preclinical, and clinical applications," Advanced Drug Delivery Reviews, 2012.

[5] C. G. Cameron and M. S. Freund, "Electrolytic actuators: Alternative, high-performance, materialbased devices," Proceedings of the National Academy of Sciences of the United States of America, vol. 99, pp. 7827-7827-7831, 2002. 
[6] C. R. Neagu. (1998). A medical microactuator based on an electrochemical principle. Available: http://doc.utwente.nl/13878

[7] C. Neagu, H. Jansen, H. Gardeniers, and M. Elwenspoek, "The electrolysis of water: an actuation principle for MEMS with a big opportunity," Mechatronics, vol. 10, pp. 571-81, 2000.

[8] T. Stanczyk, B. Ilic, P. J. Hesketh, and J. G. Boyd Iv, "Microfabricated electrochemical actuator for large displacements," Journal of Microelectromechanical Systems, vol. 9, pp. 314-320, 2000.

[9] S. Bohm, B. Timmer, W. Olthuis, and P. Bergveld, "Closed-loop controlled electrochemically actuated micro-dosing system," Journal of Micromechanics and Microengineering, vol. 10, pp. 498-504, 2000.

[10] H. Suzuki and R. Yoneyama, "A reversible electrochemical nanosyringe pump and some considerations to realize low-power consumption," Sensors and Actuators B: chemical, vol. 86, pp. 242-250, 2002.

[11] H. Suzuki and R. Yoneyama, "Integrated microfluidic system with electrochemically actuated on-chip pumps and valves," Sensors and Actuators B (Chemical), vol. B96, pp. 38-45, 2003.

[12] P.-Y. Li, J. Shih, R. Lo, S. Saati, R. Agrawal, M. S. Humayun, et al., "An electrochemical intraocular drug delivery device," Sensors and Actuators A: Physical, vol. 143, pp. 41-48, 2008.

[13] H. Gensler, R. Sheybani, L. Po-Ying, R. Lo, S. Zhu, Y. Ken-Tye, et al., "Implantable MEMS drug delivery device for cancer radiation reduction," in 23rd IEEE International Conference on Micro Electro Mechanical Systems, MEMS 2010, Hong Kong, 2010, pp. 23-6.

[14] H. Gensler, R. Sheybani, P.-Y. Li, R. L. Mann, and E. Meng, "An implantable MEMS micropump system for drug delivery in small animals," Biomedical Microdevices, vol. 14, pp. 483-496, 2012.

[15] R. Sheybani, H. Gensler, and E. Meng, "Rapid and repeated bolus drug delivery enabled by high efficiency electrochemical bellows actuators," in 2011 16th International Solid-State Sensors, Actuators and Microsystems Conference, Transducers '11 Beijing, China, 2011, pp. 490-3.

[16] K. Broka and P. Ekdunge, "Oxygen and hydrogen permeation properties and water uptake of Nafion 117 membrane and recast film for PEM fuel cell," Journal of Applied Electrochemistry, vol. 27, pp. 117-23, 1997.

[17] S. Grigoriev, P. Millet, K. Dzhus, H. Middleton, T. Saetre, and V. Fateev, "Design and characterization of bi-functional electrocatalytic layers for application in PEM unitized regenerative fuel cells," International Journal of Hydrogen Energy, vol. 35, pp. 5070-5076, 2010.

[18] S. Song, H. Zhang, X. Ma, Z.-G. Shao, Y. Zhang, and B. Yi, "Bifunctional oxygen electrode with corrosion-resistive gas diffusion layer for unitized regenerative fuel cell," Electrochemistry Communications, vol. 8, pp. 399-405, 2006.

[19] T. Ioroi, K. Yasuda, Z. Siroma, N. Fujiwara, and Y. Miyazaki, "Thin film electrocatalyst layer for unitized regenerative polymer electrolyte fuel cells," Journal of Power Sources, vol. 112, pp. 583-7, 2002.

[20] P. Choi, D. G. Bessarabov, and R. Datta, "A simple model for solid polymer electrolyte (SPE) water electrolysis," in 14th International Conference on Solid State Ionics (SSI-14), 22-27 June 2003, Monterey, CA, 2004, pp. 535-9.

[21] J. Fall, D. Humphreys, and S. Guo, "Design and Testing of a Unitized Regenerative Fuel Cell," Journal of fuel cell science and technology, vol. 6, 2009.

[22] J. Zhang, X. Wang, J. Hu, B. Yi, and H. Zhang, "A novel method for preparing pemfc catalytic layers," Bull Chem Soc Japan, vol. 77, pp. 2289-90, 2004.

[23] A. Verma and S. Basu, "Feasibility study of a simple unitized regenerative fuel cell," Journal of power sources, vol. 135, pp. 62-65, 2004.

[24] R. Sheybani, H. Gensler, T. Hoang, and E. Meng, "Novel Wirelessly-operated Implantable Dug Infusion Micropump for On-demand, Site-specific Delivery of Pain Medications," in 14th World Congress on Pain, Milan, Italy, 2012.

[25] R. Sheybani, H. Gensler, and E. Meng, "A MEMS electrochemical bellows actuator for fluid metering applications," Biomedical Microdevices, pp. 1-12, 2012/07/01 2012. 
[26] R. Sheybani and E. Meng, "High-Efficiency MEMS Electrochemical Actuators and Electrochemical Impedance Spectroscopy Characterization," Microelectromechanical Systems, Journal of, vol. 21, pp. 1197-1208, 2012.

[27] G. Chen, H. Zhang, J. Cheng, Y. Ma, and H. Zhong, "A novel membrane electrode assembly for improving the efficiency of the unitized regenerative fuel cell," Electrochemistry communications, vol. 10, pp. 1373-1376, 2008.

[28] D. Linden, Handbook of batteries, 2nd ed.: McGraw-Hill, 1995.

[29] C. Song and J. Zhang, "Electrocatalytic Oxygen Reduction Reaction," in PEM Fuel Cell Electrocatalysts and Catalyst Layers, J. Zhang, Ed., ed: Springer London, 2008, pp. 89-134.

[30] Perma Pure. (2014). Nafion: Physical and Chemical Properties. Available: http://www.permapure.com/products/nafion-tubing/nafion-physical-and-chemical-properties/

[31] S. Goswami, S. Klaus, and J. Benziger, "Wetting and absorption of water drops on Nafion films," Langmuir, vol. 24, pp. 8627-8633, 2008.

[32] H. Gensler, R. Sheybani, and E. Meng, "Rapid non-lithography based fabrication process and characterization of Parylene C bellows for applications in MEMS electrochemical actuators," in 16th International Solid-State Sensors, Actuators and Microsystems Conference, Transducers '11, Beijing, China, 2011, pp. 2347-2350.

[33] H. Gensler and E. Meng, "Rapid fabrication and characterization of MEMS Parylene C bellows for large deflection applications," Journal of Micromechanics and Microengineering, vol. 22, p. 115031, 2012 .

Roya Sheybani received her B.S. (2008) and M.S. (2009) degrees in biomedical engineering from the University of Southern California (USC), Los Angeles, where she is currently a $\mathrm{PhD}$ candidate in biomedical engineering. She is a member of Tau Beta Pi and was coauthor of an Outstanding Paper Award from the 15th International Conference on Solid-State Sensors, Actuators and Microsystems. She also received the best poster award at the 16th Annual Fred S. Grodins Graduate Research Symposium (Grodins, 2012) and the 2nd place Wallace H. Coulter Translational Research Partnership innovation award (2013). She is developing closed-loop implantable wireless MEMS drug delivery devices for management of chronic diseases.

Ellis Meng (M'02-SM'09) received her B.S. degree in engineering and applied science and her M.S. and $\mathrm{Ph} . \mathrm{D}$. degrees in electrical engineering from the California Institute of Technology (Caltech), Pasadena, in 1997, 1998, and 2003, respectively. She is a Professor of Biomedical Engineering and Electrical Engineering at the University of Southern California, Los Angeles where she has been since 2004. She directs the Biomedical Microsystems Laboratory which specializes in bio-microelectromechanical systems, implantable biomedical microdevices, neural interfaces, and microfluidics. She is a recipient of the NSF CAREER, the Wallace H. Coulter Foundation Early Career Translational Research, and the ASEE Curtis W. McGraw Research Awards. In 2009, she was recognized as one of the TR35 Technology Review Young Innovators under 35. 
- Recombination of gases an important factor for electrolysis actuators and unitized regenerative fuel cells

- Increased speed, consistency, and repeatability of gas recombination in electrolysis microactuators

- Developed methods to increase the catalyst surface area, hydrophobicity, and availability for recombination

- Pyrolyzed-Nafion ${ }^{\circledR}$-coated Pt segments in the electrolyte accelerated recombination by 2.3 times

- Reduced variability in recombination under varying actuator orientations 